Article

\title{
Representing Organic Compound Oxidation in Chemical Mechanisms for Policy-Relevant Air Quality Models under Background Troposphere Conditions
}

\author{
Richard G. Derwent ${ }^{(D)}$ \\ Rdscientific, Berkshire, Newbury RG14 6LH, UK; r.derwent@btopenworld.com
}

Received: 9 December 2019; Accepted: 5 February 2020; Published: 7 February 2020

\begin{abstract}
This intercomparison has taken thirteen chemical mechanisms and compared how they treat VOC oxidation and degradation and its relationship to the photochemical formation of ozone and hydroxyl radicals. Here, we have looked in some detail at the incremental responses of hydroxyl radicals to incremental additions of a range of organic compounds under conditions appropriate to the background atmosphere. Most of the time, with most organic compounds and most chemical mechanisms, incremental additions of an organic compound led to depletion of hydroxyl radical concentrations. The chemical mechanisms studied demonstrated increasingly negative incremental hydroxyl radical reactivities with increasing carbon numbers for the alkanes ethane, propane and n-butane. Hydroxyl radical incremental reactivities for the simple alkenes, ethylene and propylene, were reasonably consistent across the chemical mechanisms studied. However, this consistent representation did not extend to trans but-2-ene, where reactivity estimates spanned a range of a factor of five. Incremental reactivities were reasonably well-defined for isoprene which was encouraging in view of its importance to background tropospheric chemistry. The most serious discrepancies emerging from this study were found with the aromatics toluene and o-xylene, and with the Master Chemical Mechanism and these are discussed in some detail.
\end{abstract}

Keywords: photochemical smog; volatile organic compounds; chemical mechanisms; air; quality models

\section{Introduction}

Air quality models are employed by policy-makers to formulate emission control strategies with a view to combatting photochemical air pollution, particulate matter and acid rain in Europe, Asia and North America. Chemical mechanisms are essential components of air quality models because ozone $\left(\mathrm{O}_{3}\right)$ is a secondary pollutant that is not emitted into the atmosphere. Ozone is formed by photochemical reactions in the sunlit atmosphere from emitted precursors: oxides of nitrogen $\left(\mathrm{NO}_{\mathrm{x}}\right)$ and volatile organic compounds (VOCs). Hence air quality policies and strategies, and the models that address them, have to focus on the $\mathrm{NO}_{\mathrm{x}}$ and VOC precursors. Tackling elevated ozone levels is a major policy activity because ozone is an important air pollutant that at elevated levels damages human health and vegetation and also contributes to climate change [1].

The chemical mechanisms in air quality models incorporate information on the chemical kinetics and pathways that transform the primary emitted precursor pollutants into secondary pollutants, particularly ozone and suspended particulate matter. It is essential that these chemical mechanisms faithfully represent the actual chemistry of the real world if the derived policies are to deliver the required improvements in air quality. If the chemical mechanisms contain inadequately characterised representations of important atmospheric chemistry processes, then the policy predictions may 
underestimate the emissions reductions required or may overstate them, causing unnecessary implementation costs. How are chemical mechanisms to be evaluated? Perhaps more importantly, how are chemical mechanisms to be chosen for particular air quality policy modelling applications from the plethora of available chemical mechanisms? Chemical mechanism selection has been a difficult issue for regulatory policy development since the early days [2]. These concerns still exist [3,4]. These difficulties are compounded by the often limited choice of chemical mechanisms available within the widely used air quality modelling systems because chemical mechanisms are not offered on a plug-and-play basis as with meteorological parameterisations, for example. Where differences in policy-relevant predictions have been found by substituting different chemical mechanisms as in, for example [5], there is then the difficulty of proving which predictions are correct.

In previous chemical mechanism intercomparison studies, the impact of different chemical mechanisms for air quality policy formulation have been investigated under North American [6] and European [7] conditions. Here the focus is more global in context, rather than regional, as policy attention has shifted to the background troposphere. This change in emphasis reflects the shift in the attention of policy-makers to address the intercontinental transport of ozone [8-11], the issue of the policy-relevant ozone background across the United States of America [12-21] the global burden of disease resulting from air pollution $[22,23]$ and the linkage between air quality and climate change [11,24-29].

There are several aspects of chemical mechanism development that could be compared and assessed in an intercomparison. In this study, attention is focussed on the representation of the oxidation and degradation of the organic compounds and its relationship to the photochemical formation of ozone and hydroxyl $(\mathrm{OH})$ radicals. The representation of these processes presents a formidable challenge to mechanism developers because of their complexity, because of the myriad of organic compounds that need to be considered and because of the limited nature of current understanding. Mechanism developers inevitably have to rely on approximations, assumptions and in many cases, important processes have to be neglected altogether. To enable a fair intercomparison of the representation of the oxidation and degradation chemistry of organic compounds in each chemical mechanism, a common basis has to be established so that the main differences between the chemical mechanisms are highlighted and brought to the fore. Attention is given to the photochemical ozone production rates and the $\mathrm{OH}$ number densities in the base case and their responses to incremental additions of organic compounds.

\section{Methodology}

A zero-dimensional box model was set up to provide a framework for the intercomparison and evaluation of the thirteen chemical mechanisms. The focus of the intercomparison was on $\mathrm{O}_{3}$ and $\mathrm{OH}$ radicals, together with other reactive free radical species. In the paragraphs below, the background environmental conditions underpinning the intercomparison are described. Attention is then directed to the implementation of the chemical mechanisms themselves. Finally, a description is given of the chemical development in the box model and how the mixing ratios of the box model species were constrained to the background environmental conditions.

The formulation of the box model was based on the Photochemical Trajectory Model (PTM), the details of which are given elsewhere [30]. In this application, wet and dry deposition, exchange with the free troposphere and emission processes have been switched off, leaving the complete focus on the chemical development of photochemical ozone and that of the hydroxyl $(\mathrm{OH})$ radical species that drives it.

Table 1 summarises the details of the thirteen chemical mechanisms studied, together with their literature references. They varied marked in complexity from the highly detailed and explicit Master Chemical Mechanism (MCM) v3.3.1 to the highly condensed Carbon Bond and SAPRC mechanisms. Our focus was principally on the background troposphere and the regional and global chemistry-transport models used in policy formulation and assessment on the regional and hemispheric 
scales. Each of the major chemical mechanisms studied here has undergone frequent updating and no attempt has been made to keep track of these. There is no implication underpinning our choice of mechanism and version that we consider them to be of more policy importance than any other. For most chemical mechanisms, there are a range of versions spanning many years of development and, again, our choice of version is completely arbitrary.

Table 1. Details of the chemical mechanisms implemented in this intercomparison study. Italics are used to signify those mechanisms that have not been implemented as originally developed but have been harmonised and standardised, see text.

\begin{tabular}{cc}
\hline Mechanism & Remarks \\
\hline CBM4 & 52 species, 88 reactions; note a \\
CB05 & 62 species, 140 reactions; note $\mathrm{b}$ \\
CR6 & 82 species, 212 reactions; note c \\
EMEP & 484 species, 574 reactions; note $\mathrm{d}$ \\
GEOS-CHEM & 83 species, 151 reactions; note $\mathrm{e}$ \\
Leeds Master Chemical Mechanism (MCM v3.3.1) & 98 species, 273 reactions; note $\mathrm{f}$ \\
MELCHIOR2 (CHIMERE) & 1556 species, 4793 reactions; note $\mathrm{g}$ \\
MOZART4 & 56 species, 133 reactions; note $\mathrm{h}$ \\
RADM & 93 species, 196 reactions; note $\mathrm{i}$ \\
RACM2 & 48 species, 95 reactions; note $\mathrm{j}$ \\
SAPRC-99 & 124 species, 364 reactions; note $\mathrm{k}$ \\
SAPRC-07 (CS07A) & 82 species, 218 reactions; note 1 \\
\end{tabular}

Notes: a. [31]. b. CAMx mechanism 6: CB05 gas-phase chemistry, Appendix C, CAMx User's Guide Version 6.2, Environ International Corporation, Novato, California, March 2015, [32]. c. CAMx mechanism 2: CBr6 gas-phase chemistry, Appendix A, [32]. d. http://mcm.york.ac.uk/MCM, [33]. e. Default chemistry EmChem09 [34] f. GEOS-Chemv9-02f (accepted 07 Feb 2013): downloaded from http://wiki.seas.harvard.edu/geos-chem/index.php/ updating standard chemistry with JPL 10-6\#Species [35]. g. http://mcm.york.ac.uk/MCM, [36]. h. MELCHIOR2 is a condensed version of MELCHIOR1; [37]. i. [38]. j. [39]. k. RACM2.5M4c [40]. 1. CAMx mechanism 5: SAPRC99 gas-phase chemistry, Appendix D [32]. m. CS07A is the most highly condensed version of SAPRC-07: [41].

The mechanisms were, however, not implemented as published but were harmonised to minimise the influence of publication date which spanned four decades from RADM to CRIv2.2. The first harmonisation addressed the so-called 'inorganic chemistry'. This set of chemical reactions establishes the fast photochemical balance and involves the hydroxyl $(\mathrm{OH})$, hydroperoxy $\left(\mathrm{HO}_{2}\right)$ and oxygen $\left(\mathrm{O}^{1} \mathrm{D}\right.$ and $\left.\mathrm{O}^{3} \mathrm{P}\right)$ atoms and their reactions with nitric oxide $(\mathrm{NO})$, nitrogen dioxide $\left(\mathrm{NO}_{2}\right)$, ozone $\left(\mathrm{O}_{3}\right)$, water vapour, carbon monoxide $(\mathrm{CO})$, hydrogen $\left(\mathrm{H}_{2}\right)$ and sulphur dioxide $\left(\mathrm{SO}_{2}\right)$. The 'inorganic chemistry' provided with each mechanism was removed and replaced with a set of 49 chemical reaction pathways and rate coefficients, together with their temperature and pressure dependences, taken from IUPAC (http://iupac.pole-ether.fr/) [42].

The second harmonisation involved the photolysis rate coefficients. The photolysis rate coefficients provided with each mechanism were replaced with a standard set taken from the MCM website (http://mcm.york.ac.uk/MCM) [33]. The final harmonisation involved the rate coefficients for the formation and decomposition of the peroxyacyl nitrates and for the reactions of the methyl peroxy $\left(\mathrm{CH}_{3} \mathrm{O}_{2}\right)$ radical. Again, these were removed and replaced with a standard set of rate coefficients, together with their pressure and temperature dependences taken from the MCM website (http: //mcm.york.ac.uk/MCM) [33].

It is understood that these harmonisation steps may well move the mechanisms away from the conditions and chemical regimes under which they were developed by their originators. This was considered inevitable. As a result, the performance of the mechanisms may be different from that if no changes had been made. To draw attention to the harmonisation and standardisation steps, the names of the mechanisms have been printed in italics to indicate that they have not been implemented as originally developed. 
Any intercomparison of chemical mechanisms needs input data on background environmental conditions to set up an appropriate chemical regime to frame the evaluation. In this study, output has been taken from a global Lagrangian chemistry-transport model (STOCHEM-CRI) [43] and was used to provide realistic mixing ratios for a number of trace gases in the box model. These trace gases, of which there are thirty in all see Table 2, included closed-shell ozone precursors and reaction products with atmospheric lifetimes of the order of minutes and longer. Free radical species have much shorter lifetimes and were not set up in the same way but allowed to establish their own levels based on the time-dependent photochemical activity.

Table 2. Mixing ratios and environmental conditions employed to set up the box model study, together with atmospheric densities and water vapour concentrations in molecule $\mathrm{cm}^{-3}$.

\begin{tabular}{cccc}
\hline Species & Range & Species & Range \\
\hline $\mathrm{NO}_{\mathbf{x}}$ & & Products & \\
$\mathrm{NO}$ & $16-114 \mathrm{ppt}$ & $\mathrm{O}_{3}$ & $36-98 \mathrm{ppb}$ \\
$\mathrm{NO}_{2}$ & $201-1564 \mathrm{ppt}$ & $\mathrm{HNO}_{3}$ & $164-1192 \mathrm{ppt}$ \\
& & $\mathrm{PAN}$ & $130-2684 \mathrm{ppt}$ \\
VOCs & $\mathrm{MPAN}$ & $2.5-104 \mathrm{ppt}$ \\
$\mathrm{CH}_{4}$ & $1686-1777 \mathrm{ppb}$ & $\mathrm{H}_{2} \mathrm{O}_{2}$ & $1.18-3.48 \mathrm{ppb}$ \\
$\mathrm{C}_{2} \mathrm{H}_{6}$ & $517-1775 \mathrm{ppt}$ & $\mathrm{CH}_{3} \mathrm{OOH}$ & $129-413 \mathrm{ppt}$ \\
$\mathrm{C}_{3} \mathrm{H}_{8}$ & $67-637 \mathrm{ppt}$ & $\mathrm{HCHO}$ & $0.9-7.3 \mathrm{ppb}$ \\
$\mathrm{C}_{4} \mathrm{H}_{10}$ & $148-2101 \mathrm{ppt}$ & $\mathrm{CH}_{3} \mathrm{CHO}$ & $82-1146 \mathrm{ppt}$ \\
$\mathrm{C}_{2} \mathrm{H}_{4}$ & $147-1209 \mathrm{ppt}$ & $\mathrm{C}_{2} \mathrm{H}_{5} \mathrm{CHO}$ & $2.7-37 \mathrm{ppt}$ \\
$\mathrm{C}_{3} \mathrm{H}_{6}$ & $69-439 \mathrm{ppt}$ & $\mathrm{CH}_{3} \mathrm{OH}$ & $352-677 \mathrm{ppt}$ \\
trans but-2-ene & $0.4-4 \mathrm{ppt}$ & methyl ethyl ketone & $26-356 \mathrm{ppt}$ \\
$\mathrm{C}_{2} \mathrm{H}_{2}$ & $119-1229 \mathrm{ppt}$ & acetone & $674-2359 \mathrm{ppt}$ \\
$\mathrm{C}_{6} \mathrm{H}_{6}$ & $30-411 \mathrm{ppt}$ & & \\
toluene & $10-215 \mathrm{ppt}$ & Other data & \\
o-xylene & $1.9-34 \mathrm{ppt}$ & atmospheric density & $2.0-2.4 \times 10^{19}$ \\
isoprene & $85-1713 \mathrm{ppt}$ & temperature & $276-295 \mathrm{~K}$ \\
$\alpha-$ pinene & $11-55 \mathrm{ppt}$ & water vapour & $1.1-4.8 \times 10^{17}$ \\
$\beta$-pinene & $10-82 \mathrm{ppt}$ & zenith angle & $1 \mathrm{st} \mathrm{July}$ \\
Other species & & & \\
$\mathrm{CO}$ & $107-201 \mathrm{ppb}$ & & \\
$\mathrm{H}_{2}$ & $487-511 \mathrm{ppb}$ & & \\
\hline
\end{tabular}

The background environmental data were taken from the STOCHEM-CRI model for a grid of 108 points at $20^{\circ}$ intervals, covering a region between $60^{\circ} \mathrm{N}$ and $60^{\circ} \mathrm{S}$, near-ground, 1st July and are summarised in Table 2. For further details of the STOCHEM-CRI model [43]. Not all of these species were represented in each chemical mechanism and so care had to be taken not to introduce bias into the model results with any chemical mechanism through the choice of background environmental conditions. Since some mechanisms relied heavily on lumped VOC emission surrogates, VOC coverage was limited to common VOCs and to those explicitly or near-explicitly represented in all chemical mechanisms. The background data therefore necessarily represented the minimum or lowest common denominator approach so as not the introduce bias between the highly detailed and highly reduced chemical mechanisms.

In a box model, a differential equation of the form

$$
\mathrm{dc}_{\mathrm{i}} / \mathrm{dt}=\mathrm{P}_{\mathrm{i}}-\mathrm{l}_{\mathrm{i}} \cdot \mathrm{c}_{\mathrm{i}}
$$

was set up for each model species, $i$, where $c_{i}$ is the concentration of species, $i$, in the box, $P_{i}$ is its production rate from emissions, chemistry and boundary conditions and $l_{i}$ is the first order loss coefficient arising from chemistry, deposition and boundary conditions. In a constrained box model, the above differential equation is modified by the addition of a flux, $F_{i}$, to the right hand side of the 
equation so that the rate of change of the constrained species, $\mathrm{i}$, as listed in Table 2, remains zero and its concentration remains constant at the constrained value, $\mathrm{c}_{\mathrm{i}}{ }^{*}$ :

$$
\mathrm{dc}_{\mathrm{i}} / \mathrm{dt}=0=\mathrm{P}_{\mathrm{i}}-\mathrm{l}_{\mathrm{i}} \cdot \mathrm{c}_{\mathrm{i}}^{*}+\mathrm{F}_{\mathrm{i}}
$$

The Gear's method automatic numerical integrator FACSIMILE [44] returns the flux, $\mathrm{F}_{\mathrm{i}}$, required at the end of each time step to maintain the concentrations of each species at its constraint. This flux, which is diurnally-varying through the time-dependent photolysis rates, is then integrated over a time period of 5 days to give the time-integrated production or loss flux (depending on its sign) for that species. The output of the constrained box model is therefore the time-integrated production or loss fluxes for each of the thirty constrained species in Table 2. Particular focus was given in this study to the time-integrated ozone production flux, $\mathrm{P}_{\mathrm{O} 3}$.

For the many species without constrained values in Table 1, these species would reach some form of local instantaneous photochemical steady state and their time varying concentrations would be set by equations of the form of (1) above. Their concentrations were averaged over the 5-day time period and provided another component of the output from the constrained box model. Particular focus was given to the 5-day average hydroxyl radical number density, $[\underline{\mathrm{OH}}]$, in this study.

\section{Testing and Evaluating the Constrained Box Model}

The constrained box model was set up with each of the thirteen reduced chemical mechanisms and each set of 108 sets of background conditions and was integrated for five days. For each set of conditions and each chemical mechanism, the $\mathrm{P}_{\mathrm{O} 3}$ and $[\underline{\mathrm{OH}}]$ values were noted, and these comprised the base case results for each chemical mechanism. $\mathrm{P}_{\mathrm{O} 3}$ for MCMv3.3.1 varied from -0.5 ppt per hour to $11 \mathrm{ppb}$ per hour over the 108 sets of conditions, with an average of $1.1 \mathrm{ppb}$ per hour. The $\mathrm{P}_{\mathrm{O} 3}$ values were closely similar between the different chemical mechanisms and closely tracked each other across the different sets of conditions. Scatter plots were constructed between the base case $\mathrm{P}_{\mathrm{O} 3}$ results for each reduced chemical mechanism versus the MCMv3.3.1 results. Linear regression equations were fitted through each scatter plot, revealing excellent correlations with $\mathrm{R}^{2}$ values consistently greater than 0.99 , slopes that were close to unity and intercepts that were statistically indistinguishable from zero. $\mathrm{P}_{\mathrm{O} 3}$ values closely overlapped and average intermechanism differences from the MCMv3.3.1 were within the range $-0.6 \%$ to $+0.4 \%$ across all 108 sets of background conditions and are plotted out in Figure 1 .

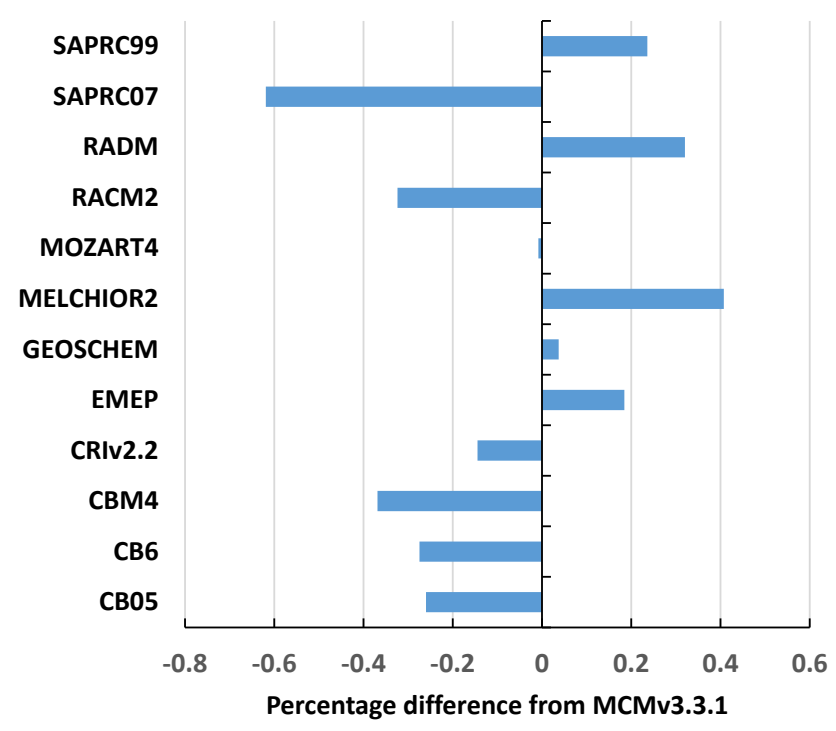

Figure 1. Average percentage differences from the MCMv3.3.1 in the base case ozone production rates in ppb per hour across the 108 sets of background conditions. 
$[\underline{\mathrm{OH}}]$ for the MCMv3.3.1 varied from 0.3 to $3.6 \times 10^{6}$ molecule $\mathrm{cm}^{-3}$, with an average of $1.6 \times 10^{6}$ molecule $\mathrm{cm}^{-3}$. Again, $[\underline{\mathrm{OH}}]$ values were closely similar between the different chemical mechanisms. However, there was much more variability between the chemical mechanisms and sets of conditions compared to $\mathrm{P}_{\mathrm{O} 3}$. Scatter plots were constructed between $[\underline{\mathrm{OH}}]$ for each chemical mechanism versus MCMv3.3.1 and linear regression equations were fitted through the scatter plots. Correlations were good with $R^{2}$ values generally greater than 0.98 . The slopes and intercepts were generally indistinguishable from zero. Average intermechanism differences were generally in the range $-4 \%$ to $+8 \%$, see Figure 2 , (RADM results excluded).

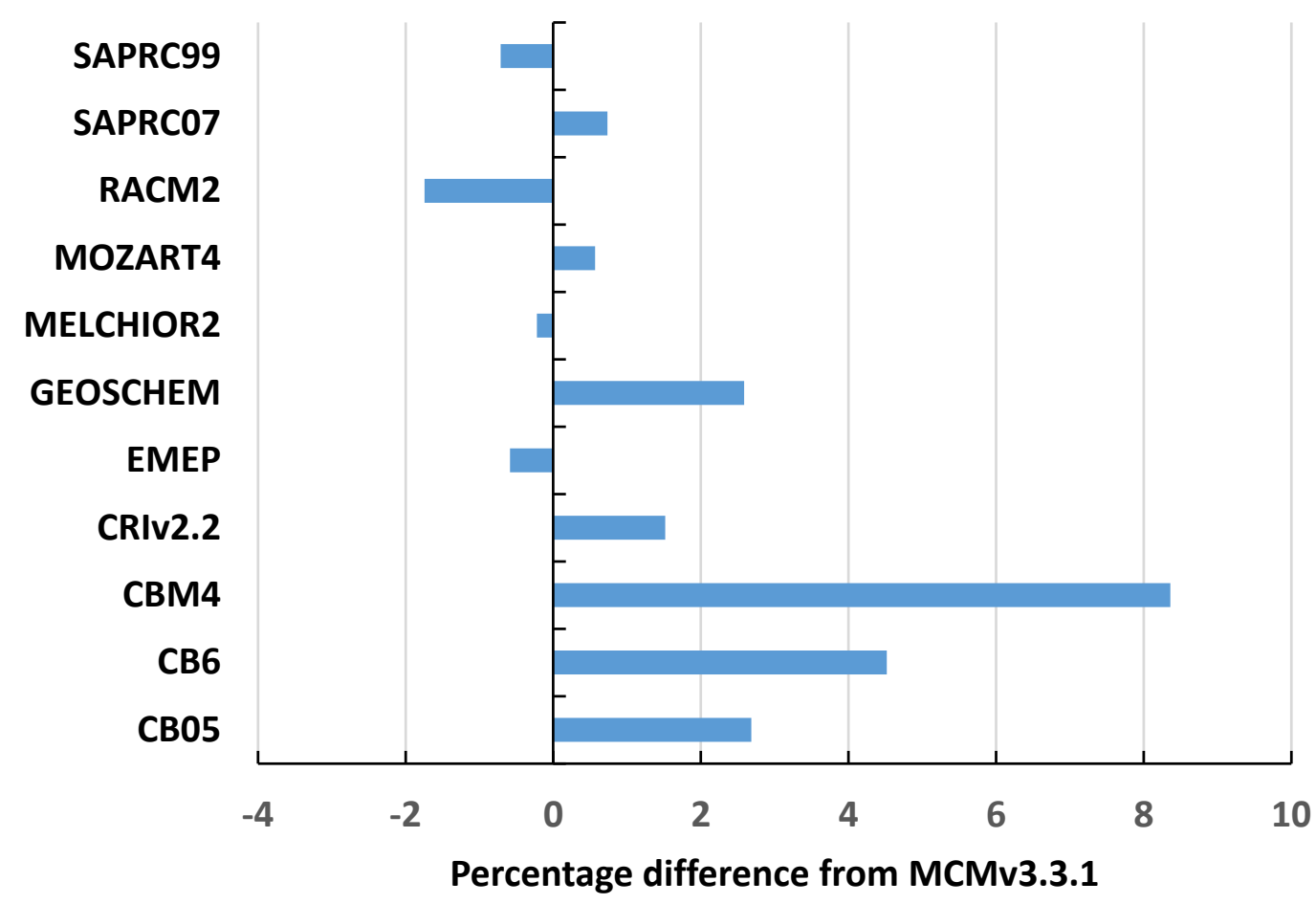

Figure 2. Average percentage differences from the MCMv3.3.1 in the five-day mean hydroxyl radical number densities across the 108 sets of background conditions.

This close agreement in $\mathrm{P}_{\mathrm{O} 3}$ and $[\underline{\mathrm{OH}}]$ between the chemical mechanisms confirmed the view that the standardisation and harmonisation steps had not introduced significant bias between the chemical mechanisms.

\section{Comparing the Impact of Organic Compounds on Background Tropospheric Chemistry}

\subsection{Overview}

For the purposes on this intercomparison, we consider that organic compounds exert two major impacts on tropospheric chemistry. In the first, the hydroxyl radical driven degradation of an organic compound leads to the formation of hydroperoxy and organic peroxy radicals $\left(\mathrm{RO}_{2}\right)$ which oxidise nitric oxide $(\mathrm{NO})$ to nitrogen dioxide $\left(\mathrm{NO}_{2}\right)$, and hence producing ozone $\left(\mathrm{O}_{3}\right.$ This impact is most important in urban areas and in the polluted atmospheric boundary layer where there are abundant sources of nitrogen oxides $\left(\mathrm{NO}_{\mathrm{x}}=\mathrm{NO}+\mathrm{NO}_{2}\right)$. However, in the background troposphere, the subject of this intercomparison, it is of diminished policy importance because background tropospheric chemistry is generally $\mathrm{NO}_{x}$-limited.

In the second major impact of organic compounds on tropospheric chemistry, the hydroxyl radical driven degradation of organic compounds changes the sources and sinks of the major free radical species: hydroxyl $(\mathrm{OH})$, hydroperoxy $\left(\mathrm{HO}_{2}\right)$ and organic peroxy $\left(\mathrm{RO}_{2}\right)$ radicals. Since background tropospheric chemistry is generally free radical limited then these changes may be of some significance. 
Changes to the sources and sinks of the hydroxyl radical have an important impact on tropospheric chemistry because of the vast numbers of trace gases whose sinks are controlled by $\mathrm{OH}$ radical driven oxidation and degradation. This second major impact of organic compounds on tropospheric chemistry is therefore of immediate policy interest and is the focus of this intercomparison.

\subsection{Methodology}

The methodology chosen to address the impact of organic compounds on the major free radical species involved adding increments of each organic compound and following the changes in hydroxyl

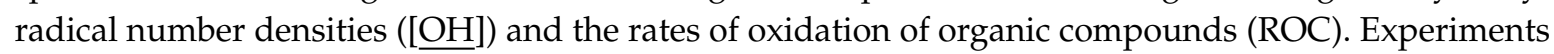
were performed with $100 \mathrm{ppt}$ ( $1 \mathrm{ppt}=1$ part in $10^{12}$ parts of air) increments of each organic compound from $100 \mathrm{ppt}$ up to $500 \mathrm{ppt}$ at each of the 108 background locations. This methodology gave four differences $(\Delta)$ : 100 ppt vs. 200 ppt, 200 ppt vs. 300 ppt and so on. For each difference, the following hydroxyl radical incremental reactivity (IROC) was defined and estimated:

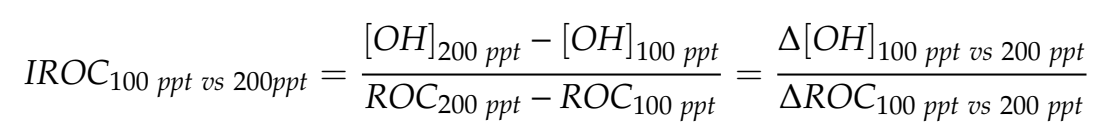

where $[\underline{\mathrm{OH}}]$ is the five-day average $\mathrm{OH}$ number density in molecule $\mathrm{cm}^{-3}$ and $\mathrm{ROC}$ is the time-averaged oxidation rate of the organic compound in ppb per hour.

To illustrate the methodology, let us consider an arbitrary example employing ethylene (ethene) $\left(\mathrm{C}_{2} \mathrm{H}_{4}\right)$ as the organic compound, the most remote of the 108 background locations and the MCMv3.3.1 mechanism. With an additional $100 \mathrm{ppt}$ increment of ethylene added, the time-averaged ethylene oxidation rate increased by $2.62 \mathrm{ppt}$ per hour and increased to $5.01 \mathrm{ppt}$ per hour with $200 \mathrm{ppt}$ added. At the same time, the five-day averaged $\mathrm{OH}$ number density declined from $4.91 \times 10^{5}$ to $4.73 \times 10^{5}$ molecule $\mathrm{cm}^{-3}$. On this basis, $\mathrm{IR}^{\mathrm{C} 2 \mathrm{H} 4} 100 \mathrm{ppt} \mathrm{vs.} 200 \mathrm{ppt}$ was found to be $(4.73-4.91) \times 10^{5} /(5.01-2.61) \times$ $10^{-3}$ molecule $\mathrm{cm}^{-3}$ per ppb hour ${ }^{-1}$, that is to say: $\mathrm{IR}^{\mathrm{C} 2 \mathrm{H} 4} 100 \mathrm{ppt}$ vs. $200 \mathrm{ppt}$ was $-7.5 \times 10^{6}$ molecule $\mathrm{cm}^{-3}$

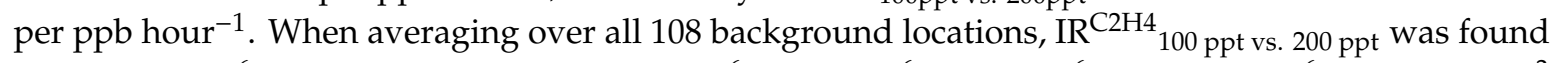
to be $-7.2 \times 10^{6}$ and this decreased to $-6.9 \times 10^{6},-6.7 \times 10^{6},-6.5 \times 10^{6}$ and $-6.5 \times 10^{6}$ molecule $\mathrm{cm}^{-3}$ per ppb hour ${ }^{-1}$ for 200 ppt vs. 300 ppt, 300 ppt vs. 400 ppt and 400 ppt vs. 500 ppt, respectively. The decline from -7.2 to $-6.5 \times 10^{6}$ molecule $\mathrm{cm}^{-3}$ per $\mathrm{ppb}$ hour ${ }^{-1}$ illustrated that the hydroxyl radical responses were not accurately linear in ethylene increments and that there was some non-linearity in the reacting system amounting to $\pm 10 \%$. Overall, it was concluded that using the MCMv3.3.1 mechanism, hydroxyl radical number densities declined with increasing ethylene additions, with an 'initial', (that is to say, 100 ppt vs. $200 \mathrm{ppt}$ ) $\mathrm{IR}^{\mathrm{C} 2 \mathrm{H} 4}$ of $-7.2 \times 10^{6}$ molecule $\mathrm{cm}^{-3}$ per ppb hour ${ }^{-1}$.

This same methodology was then applied to all thirteen organic compounds and all thirteen chemical mechanisms. The results for all the alkanes in each chemical mechanism are presented in Table 3, man-made alkenes in Table 4, biogenic alkenes and dialkenes in Table 5 and aromatics in Table 6. A rapid overview of Tables 3-6 revealed that all the organic compounds studied gave negative initial hydroxyl radical incremental reactivities. Generally speaking, incremental reactivities were smallest for the alkane class in Table 3 and largest for the aromatics in Table 6. There were, however, significant divergences between the incremental reactivities found by the different chemical mechanisms. Understanding these divergences is the main aim of this chemical mechanism intercomparison. 
Table 3. Initial ${ }^{\mathrm{a}}$ hydroxyl radical incremental reactivities for the alkanes in units of $10^{6}$ molecule $\mathrm{cm}^{-3}$ per ppb hour ${ }^{-1}$.

\begin{tabular}{cccc}
\hline Mechanism & Ethane & Propane & N-Butane \\
\hline CBM4 & -0.6 & -2.3 & -6.0 \\
CB05 & -1.2 & -4.2 & -2.9 \\
CB6 & -1.0 & -3.1 & -2.3 \\
CRIv2.2 & -0.8 & -2.7 & -4.2 \\
EMEP & -0.9 & - & - \\
GEOS CHEM & -1.0 & -3.6 & -7.3 \\
MCMv3.3.1 & -0.9 & -2.7 & -4.7 \\
MELCHIOR-2 & -1.0 & - & - \\
MOZART- -1.0 & -4.3 & - \\
RADM & -1.3 & - & - \\
RACM-2 & -1.0 & -2.1 & - \\
SAPRC-99 & - & - & -4.4 \\
SAPRC-07 & $-1.0 \pm 0.2$ & $-3.6 \pm 1.5$ & $-4.5 \pm 1.7$ \\
average &
\end{tabular}

Notes: a. 'Initial' refers to the 100 ppt vs. 200 ppt increment, see text. b. '-' the organic compound is not explicitly treated in this mechanism version.

Table 4. Initial ${ }^{\mathrm{a}}$ hydroxyl radical incremental reactivities for the alkenes in units of $10^{6}$ molecule $\mathrm{cm}^{-3}$ per ppb hour ${ }^{-1}$.

\begin{tabular}{cccc}
\hline Mechanism & Ethylene & Propylene & Trans But-2-Ene \\
\hline CBM4 & -5.8 & -4.9 & -5.0 \\
CB05 & -7.8 & -6.2 & -0.7 \\
CB6 & -7.5 & -6.4 & -1.4 \\
CRIv2.2 & -7.3 & -6.8 & -1.0 \\
EMEP & -6.1 & -6.8 & - \\
GEOS CHEM & - & -7.8 & - \\
MCMv3.3.1 & -7.2 & -6.4 & -1.0 \\
MELCHIOR-2 & -7.3 & -6.3 & - \\
MOZART-4 & -5.7 & -6.3 & - \\
RADM & -1.0 & -6.8 & -5.8 \\
RACM-2 & -8.5 & -7.9 & -1.1 \\
SAPRC-99 & -6.9 & -6.8 & -2.6 \\
SAPRC-07 & -5.8 & -6.1 & -2.0 \\
average & $-6.4 \pm 1.9$ & $-6.6 \pm 0.8$ & $-2.3 \pm 1.9$ \\
\hline
\end{tabular}

Notes: a. 'Initial' refers to the 100 ppt vs. 200 ppt increment, see text. b. '-' the organic compound is not explicitly treated in this mechanism version.

Table 5. Initial ${ }^{\mathrm{a}}$ hydroxyl radical incremental reactivities for the biogenic alkenes and alkadienes in units of $10^{6}$ molecule $\mathrm{cm}^{-3}$ per ppb hour ${ }^{-1}$.

\begin{tabular}{cccc}
\hline Mechanism & Isoprene & $\alpha$-Pinene & $\beta$-Pinene \\
\hline CBM4 & -4.9 & - & - \\
CB05 & -7.3 & -3.0 & - \\
CB6 & -7.1 & -2.8 & - \\
CRIv2.2 & -7.3 & -4.6 & -9.3 \\
EMEP & -9.7 & - & - \\
GEOS CHEM & -8.4 & - & - \\
MCMv3.3.1 & -6.5 & -4.1 & -9.3 \\
MELCHIOR-2 & -8.9 & - & - \\
MOZART-4 & -9.8 & -5.4 & - \\
RADM & - & - & - \\
RACM-2 & -8.9 & -3.0 & - \\
SAPRC-99 & -8.0 & -3.7 & - \\
SAPRC-07 & -8.9 & -3.2 & - \\
average & $-8.0 \pm 1.4$ & $-3.7 \pm 0.9$ & $-9.3 \pm 0.0$ \\
\hline
\end{tabular}

Notes: a. 'Initial' refers to the $100 \mathrm{ppt}$ vs. 200 ppt increment, see text. b. '-' the organic compound is not explicitly treated in this mechanism version. 
Table 6. Initial ${ }^{\text {a }}$ hydroxyl radical incremental reactivities for acetylene and the aromatics in units of $10^{6}$ molecule $\mathrm{cm}^{-3}$ per ppb hour ${ }^{-1}$.

\begin{tabular}{ccccc}
\hline Mechanism & Acetylene & Benzene & Toluene & O-Xylene \\
\hline CBM4 & - & - & -5.8 & -7.4 \\
CB05 & - & - & -9.8 & -10.4 \\
CB6 & -1.1 & -4.8 & -6.8 & -7.6 \\
CRIv2.2 & -1.0 & -5.7 & -10.4 & -10.7 \\
EMEP & - & - & - & -22.2 \\
GEOS CHEM & - & - & - & - \\
MCMv3.3.1 & -0.7 & -8.7 & -30.0 & -30.3 \\
MELCHIOR-2 & - & -4.2 & - & -12.4 \\
MOZART-4 & - & - & -8.3 & - \\
RADM & - & - & -4.6 & -5.7 \\
RACM-2 & -0.9 & -6.8 & -8.8 & - \\
SAPRC-99 & - & -10.5 & -12.0 & - \\
SAPRC-07 & - & -6.2 & -7.9 & - \\
average & $-0.9 \pm 0.2$ & $-6.7 \pm 2.2$ & $-10.4 \pm 7.2$ & $-13.3 \pm 8.5$ \\
\hline
\end{tabular}

Notes: a. 'Initial' refers to the 100 ppt vs. 200 ppt increment, see text. b. '-' the organic compound is not explicitly treated in this mechanism version.

\subsection{Assessing the Impact of the Alkanes on Hydroxyl Radicals}

Table 3 presents the initial hydroxyl radical incremental reactivities for the three simplest alkanes using the thirteen chemical mechanisms. Incremental reactivities were the most negative for $\mathrm{n}$-butane and least negative for ethane in almost all of the mechanisms. Averages and standard deviations of the estimates are presented in Table 3. There was a spread of values for each organic compound and, generally speaking, the values for MCMv3.3.1 were close to the mechanism average. It was concluded that most of the mechanisms were able to account reasonably accurately for the impact of alkane increments on hydroxyl radical number densities. However, incremental reactivities did span over a factor of two between CBM4 and RACM-2.

The mechanism for the hydroxyl radical-driven oxidation of ethane $\left(\mathrm{C}_{2} \mathrm{H}_{6}\right)$ laid out in the MCMv3.3.1 involves 46 chemical species, 119 chemical and photochemical reactions producing 21 stable product species including alkyl hydroperoxides, nitrates, alcohols, aldehydes and peroxyacyl nitrates. The complete mechanism represents a cascade system through the organic peroxy radicals, ethyl peroxy, acetyl peroxy, methyl peroxy and hydroperoxyl, after the initial attack of $\mathrm{OH}$ on ethane:

$$
\mathrm{OH}+\mathrm{C}_{2} \mathrm{H}_{6}=\mathrm{C}_{2} \mathrm{H}_{5} \mathrm{O}_{2} \text {. }
$$

There is therefore a single reaction which is unique to ethane and a core of 118 reactions that are used in many other VOC oxidation mechanisms. Almost all of the 119 reactions have some impact on hydroxyl radical number densities because they may be sources and sinks of free radicals or convert one free radical into another. Overall, however, the oxidation of ethane is a net sink for hydroxyl radical, as shown by the negative hydroxyl radical incremental reactivities in Table 3.

The twelve reduced or condensed mechanisms, see Table 3, appear to have reduced or condensed markedly the detail of ethane oxidation into a handful of reactions without losing any of the chemical complexity and all confirm that ethane oxidation is a net sink for hydroxyl radicals. In the CB05 mechanism, for example, the reaction of hydroxyl radicals with ethane (ETHA) is represented by:

$$
\mathrm{OH}+\mathrm{ETHA}=\mathrm{HO}_{2}+0.991 \mathrm{ALD}_{2}+0.991 \mathrm{XO}_{2}+0.009 \mathrm{XO}_{2} \mathrm{~N},
$$

where the generic organic peroxy radical $\mathrm{XO} 2$ and $\mathrm{XO} 2 \mathrm{~N}$ are shared by the degradation schemes of several hydrocarbons and the non-stoichiometric terms: 0.991 and 0.009 represent the net of the peroxy 
radical cascade system. In the SAPRC-99 mechanism, the oxidation of ethane is represented with a single generic peroxy radical product, $\mathrm{RO} 2 \_\mathrm{R}$ as:

$$
\mathrm{OH}+\mathrm{ALK} 1=\mathrm{RO}_{2} \_\mathrm{R}+\mathrm{CCHO} .
$$

At the other end of the reduced mechanism spectrum, the CRIv2.2 mechanism uses 29 species and 68 chemical reactions to describe ethane oxidation in a manner that is accurately consistent with that in the MCMv3.3.1.

The initial hydroxyl radical incremental reactivities for propane, see Table 3, were about three times more negative than those for ethane. Increments of propane therefore showed a significantly greater propensity to deplete 5-day mean hydroxyl radical number densities compared to those of ethane. This increased the propensity results from the longer organic peroxy radical cascade between propyl peroxy and hydroperoxyl. The MCMv3.3.1 oxidation scheme for propane employs 90 chemical species and 256 chemical reactions whilst that for the CRIv2.2 employs 49 and 129, respectively.

The reduced mechanisms gave a reasonably accurate account of the increased incremental hydroxyl radical reactivity for propane relative to ethane, showing that they were able to account for the significant increase in complexity in moving from ethane to propane. This increased complexity arises not only from the increased length of the peroxy radical cascade but also from the formation of relatively unreactive ketones such as acetone, compared with the highly reactive and photochemically-labile aldehydes such as acetaldehyde formed in ethane oxidation.

Initial hydroxyl radical incremental reactivities for n-butane are considerably more negative than those of propane and ethane, see Table 3. There is a noticeably increased range in the available values for n-butane compared with those for ethane which amounts to a factor three. The MCMv3.3.1 mechanism represents the oxidation of n-butane using 184 species in 550 reactions, representing a dramatic increase in complexity over and above the oxidation of propane. This follows on from the increased number of isomeric peroxy radicals and stable products, such as ketones and hydroperoxides, and the increased length of the peroxy radical cascade system.

Before moving on from the simple alkanes, we note that the initial hydroxyl radical incremental reactivities for $n$-butane, propane and ethane have the relative ratios: 1:0.85:0.2. The corresponding ratios of their $\mathrm{OH}+$ alkane rate coefficients are: 1:0.47:0.11, whereas the lengths of their oxidation mechanisms in the MCMv3.3.1 are: 1:0.47:0.21, showing no simple relationship with the incremental reactivities.

It therefore appears that in constructing mechanisms for alkane oxidation from smog chamber data or by compiling near-explicit mechanisms from individual elementary reactions, it has been possible to describe the impacts of alkanes on both ozone and hydroxyl radicals in ways that are mutually consistent. We have been able to show here that the descriptions of the impacts on photochemical ozone production rates and on 5-day mean hydroxyl radical number densities are reasonably consistent across the mechanisms. Examples will be found later where this degree of mutual consistency between photochemical ozone production rates and mean hydroxyl radical number densities is not so clearly demonstrated.

\subsection{Assessing the Impact of the Alkenes on Hydroxyl Radicals}

The hydroxyl radical incremental reactivities for the man-made alkenes are presented in Table 4 . The incremental reactivities for ethylene and propylene (propene) are similar in almost all the mechanisms (except for CBM4 and RADM) and appear to be three times more negative compared with those for trans but-2-ene. The relative ratios of the incremental reactivities for ethylene propylene trans, but-2-ene were found to be 1.0:1.0:0.3 compared to 1.0:3.2:7.8 for their $\mathrm{OH}$ rate coefficients. Since the alkenes are all highly reactive on the 5-day timescale of this study, it is not surprising that the $\mathrm{OH}$ rate coefficients give little indication of the relative hydroxyl radical incremental reactivities. In comparison, the relative numbers of reactions in the MCMv3.3.1 oxidation schemes were 1.0:2.1:1.5, respectively. 
Almost all the mechanisms indicated a strong depletion of hydroxyl radical number densities driven by additional increments of ethylene, see Table 4, except for the RADM mechanism, the oldest mechanism studied, which appears to be an outsider in this instance. The remaining mechanisms showed excellent agreement and a relatively small range about the MCMv3.3.1 value. The similarity between the incremental reactivities found for ethylene and propylene in Table 4 was somewhat surprising, as was the observations that this close similarity applied to almost all of the mechanisms studied.

There appeared to be a significantly large range in the estimates of the hydroxyl radical incremental reactivities for trans but-2-ene, one of the most reactive of all organic compounds. Despite this exceptional $\mathrm{OH}$-reactivity, its incremental hydroxyl radical incremental reactivity was found to be significantly less than that for either ethylene or propylene, see Table 4 . The range in the estimates was also significantly larger than for the other alkenes, with the MCMv3.3.1 value towards the lower end of the range of estimates.

All three alkenes are expected to generate similar first-generation reaction products, namely; ethylene oxidation generates two formaldehyde molecules, propylene generates one molecule of formaldehyde and one of acetaldehyde and trans but-2-ene generates two molecules of acetaldehyde. Hence the less negative incremental reactivity and its greater uncertainty range of the estimates for trans but-2-ene are, at first sight, somewhat surprising. We explain these discrepancies as symptoms of the difficulty mechanism developers have in reconciling both photochemical ozone production and free radical sources and sinks, in the face of incomplete and conflicting understanding of the elementary reactions involved in free radical production and loss in the $\mathrm{OH}$-oxidation of trans but-2-ene.

\subsection{Assessing the Impact of the Biogenic Alkenes and Alkadienes on Hydroxyl Radicals}

Table 5 presents the hydroxyl radical incremental reactivities for the biogenic alkenes and alkadienes. The biogenic alkenes have been separated from the man-made alkenes because of the different environments in which their atmospheric reactions become of policy significance. The biogenic alkenes are emitted in largely rural environments where $\mathrm{NO}_{\mathrm{x}}$ levels are low, compared to the man-made alkenes that are emitted mainly in urban environments with associated high $\mathrm{NO}_{\mathrm{x}}$ levels. Smog chamber studies have been largely performed under high $\mathrm{NO}_{\mathrm{x}}$ conditions and so the preparation of mechanisms for biogenic alkenes involves significantly greater extrapolation to conditions appropriate to the atmosphere. It is possible therefore that $\mathrm{OH}$ oxidation mechanisms for biogenic alkenes are necessarily somewhat more uncertain than for man-made alkenes.

The hydroxyl radical incremental reactivities for isoprene in Table 5 found with the different mechanisms span a factor of two range from -4.9 for CBM-4 to -9.8 for MOZART-4, with an average of $-7.8 \pm$ 1.4. The MCMv3.3.1 value lies at the lower end of the $1-\sigma$ confidence range with the CRIv2.2 value close to the middle of the confidence range. Overall, almost all of the mechanisms gave incremental reactivities for isoprene that were more negative than the MCMv3.3.1 value, with only $C B M-4$ returning a less negative value.

In contrast, hydroxyl radical incremental reactivities for $\alpha$-pinene were significantly less negative than those for isoprene and significantly more accurately defined as indicated by the 1- $\sigma$ confidence range. For this organic compound, the difference between the MCMv3.3.1 and CRIv2.2 mechanisms was small and significant. The MOZART-4 mechanism gave the most negative reactivity whilst $C B 6$ gave the least negative.

Hydroxyl radical incremental reactivities for $\beta$-pinene were the most negative of all the three biogenic alkenes and alkadienes. However, coverage by the available mechanisms was poor and results were limited to those from the MCMv3.3.1 and CRIv2.2 mechanisms. Both mechanisms made $\beta$-pinene between two and three times more negative than $\alpha$-pinene. 


\subsection{Assessing the Impact of the Acetylene and the Aromatics on Hydroxyl Radical Number Densities}

Incremental reactivities for the acetylene (ethyne) are presented in Table 6. Acetylene is generally considered unreactive because of its low reactivity with $\mathrm{OH}$. Estimates of its hydroxyl radical incremental reactivity are available from six mechanisms and they demonstrate that acetylene increments have a relatively weak influence on hydroxyl radical number densities. Incremental reactivities from $C B 6$ and RACM-2 lie within the ranges of those from the CRI and MCM mechanisms.

The incremental reactivities estimated for the aromatics in Table 6 present a complex picture which is difficult to resolve. Starting with benzene, we find that estimates span a wide range from MELCHIOR-2, the least negative, to SAPRC-99 the most negative. The CRIv2.2 estimate was found to be significantly less negative than the mechanism-average and the MCMv3.3.1 estimate significantly more negative. The RACM-2 and SAPRC-07 estimates were close to the average.

There was no agreement concerning the hydroxyl radical incremental reactivities for toluene (methylbenzene) and o-xylene (1:2-dimethylebenzene). There was a factor of three range between the CRIv2.2 and the MCMv3.3.1 estimates which was unusual since both mechanisms are generally close. All mechanisms gave estimates that were less negative for both toluene and o-xylene compared to the MCMv3.3.1 and many were less negative than the CRIv2.2 mechanism. The MCMv3.3.1 mechanism therefore appeared to be an outsider for both toluene and o-xylene.

\section{Discussions and Conclusions}

This intercomparison has taken twelve chemical mechanisms and compared how they treat VOC oxidation and degradation and its relationship to the photochemical formation of ozone and hydroxyl radicals. Representation of VOC chemistry represents a formidable challenge for mechanism developers because of the complexity involved and because of the sheer number of organic compounds and chemical reactions that require treatment. Mechanism developers have to rely on approximations, assumptions and, in many cases, important processes have to be neglected. Here, we have looked in some detail at the incremental responses of hydroxyl radicals to incremental additions of a range of organic compounds under conditions appropriate to the background atmosphere.

Most of the chemical mechanisms studied demonstrated increasingly negative incremental hydroxyl radical reactivities with increasing carbon numbers for the alkanes ethane, propane and n-butane. That is to say, increasing alkane oxidation rates led to increased hydroxyl radical depletion, with the depletion caused by n-butane $>$ propane $>$ ethane.

Hydroxyl radical incremental reactivities for the simple alkenes ethylene and propylene, were reasonably consistent across the chemical mechanisms studied. However, this consistent representation did not extend to trans but-2-ene where reactivity estimates spanned a range of a factor of five. Incremental reactivities were reasonably well-defined for isoprene which was encouraging in view of its importance to background tropospheric chemistry.

The most serious discrepancies emerging from this study were found with the aromatics toluene and o-xylene and with the Master Chemical Mechanism. These discrepancies are in part explained by the Master Chemical Mechanism being an assembly of reported information on elementary reactions which has not been designed for explaining aromatic $+\mathrm{NO}_{x}$ smog chamber data accurately. For the Master Chemical Mechanism to do this, an additional hydroxyl radical source had to be included [45]. Because the reduced mechanisms effectively included this additional hydroxyl radical source, they necessarily gave significantly less negative incremental hydroxyl radical reactivities for toluene and o-xylene in this intercomparison.

There is a general level of uncertainty in the understanding and representation of aromatic degradation chemistry in chemical mechanisms and their ability to represent photochemical ozone formation relative to hydroxyl radical depletion in smog chamber experiments. In view of the lack of agreement between the mechanisms, it is difficult to comment on the relative incremental reactivities for the aromatics in the real world. Further laboratory and smog chamber studies will be required 
to resolve the differences between the Master Chemical Mechanism and the condensed and reduced smog chamber mechanisms.

Funding: This intercomparison received no external funding.

Acknowledgments: R.G.D. thanks the mechanism developers and air quality modellers for help in accessing the mechanisms. However, any errors in transcribing the mechanisms into FACSIMILE decks and standardising them as described in the Methodology section are entirely his.

Conflicts of Interest: The author declares no conflict of interest.

\section{References}

1. Monks, P.S.; Archibald, A.T.; Colette, A.; Cooper, O.; Coyle, M.; Derwent, R.; Fowler, D.; Granier, C.; Law, K.S.; Mills, G.E.; et al. Tropospheric ozone and its precursors from the urban to the global scale from air quality to short-lived climate forcer. Atmos. Chem. Phys. Discuss. 2015, 15, 8889-8973. [CrossRef]

2. Dimitriades, B.; Dodge, M.C. In Proceedings of the Empirical Kinetic Modeling Approach (EKMA) Validation Workshop Held at Research Triangle Park, NC, USA, 15-16 December 1981; United States Environmental Protection Agency: Washington, DC, USA, 1983.

3. Luecken, D.; Phillips, S.; Sarwar, G.; Jang, C. Effects of using the CB05 vs. SAPRC99 vs. CB4 chemical mechanism on model predictions: Ozone and gas-phase photochemical precursor concentrations. Atmos. Environ. 2008, 42, 5805-5820. [CrossRef]

4. Cai, C.; Kelly, J.T.; Avise, J.C.; Kaduwela, A.P.; Stockwell, W.R. Photochemical modeling in California with two chemical mechanisms: Model intercomparison and response to emission reductions. J. Air Waste Manag. Assoc. 2011, 61, 559-572. [CrossRef] [PubMed]

5. Luecken, D.; Yarwood, G.; Hutzell, W. Multipollutant modeling of ozone, reactive nitrogen and HAPs across the continental US with CMAQ-CB6. Atmos. Environ. 2019, 201, 62-72. [CrossRef]

6. Derwent, R. Intercomparison of chemical mechanisms for air quality policy formulation and assessment under North American conditions. J. Air Waste Manag. Assoc. 2017, 67, 789-796. [CrossRef] [PubMed]

7. Derwent, R.G. Intercomparison of chemical mechanisms for European air quality policy formulation and assessment. In Air Pollution Modeling and its Applications XXV; Springer Proceedings in Complexity; Mensink, C., Kallos, G., Eds.; Springer International Publishing: Cham, Switzerland, 2018; Chapter 10; pp. 63-67.

8. Duncan, B.N.; West, J.J.; Yoshida, Y.; Fiore, A.M.; Ziemke, J.R. The influence of European pollution on ozone in the Near East and northern Africa. Atmos. Chem. Phys. 2008, 8, 2267-2283. [CrossRef]

9. Fiore, A.M.; Dentener, F.J; Wild, O.; Cuvelier, C.; Schultz, M.G.; Hess, P.; Textor, C.; Schulz, M.; Doherty, R.M.; Horowitz, L.W.; et al. Multi-model estimates of intercontinental source-receptor relationships for ozone pollution. J. Geophys. Res. 2009, 114, D04301. [CrossRef]

10. HTAP. Hemispheric Transport of Air Pollution 2010. Part A: Ozone and Particulate Matter; Air Pollution Studies No. 17; United Nations: Geneva, Switzerland, 2010.

11. Prather, M.; Gauss, M.; Berntsen, T.; Isaksen, I.; Sundet, J.; Bey, I.; Brasseur, G.; Dentener, F.; Derwent, R.; Stevenson, D.; et al. Fresh air in the 21st century? Geophys. Res. Lett. 2003, 30, 1100. [CrossRef]

12. Baker, K.R.; Emery, C.; Dolwick, P.; Yarwood, G. Photochemical grid model estimates of lateral boundary conditions to ozone and particulate matter across the continental United States. Atmos. Environ. 2015, 123, 49-62. [CrossRef]

13. Doherty, R.M. Ozone pollution from near and far. Nature Geoscience, News and Views, 10 August 2015.

14. Dolwick, P.; Akhtar, F.; Baker, K.R.; Possiel, N.; Simon, H.; Tonnesen, G. Comparison of background ozone estimates over the western United States based on two separate model methodologies. Atmos. Environ. 2015, 109, 282-296. [CrossRef]

15. Emery, C.; Jung, J.; Downey, N.; Johnson, J.; Jimenez, M.; Yarwood, G.; Morris, R. Regional and global modeling estimates of policy relevant background ozone over the United States. Atmos. Environ. 2012, 47, 206-217. [CrossRef]

16. Fiore, A.M.; Jacob, D.J.; Bey, I.; Yantosca, R.M.; Field, B.D.; Fusco, A.C. Background ozone over the United States in summer: Origin, trend and contribution to pollution episodes. J. Geophys. Res. 2002, 107, D4275. [CrossRef] 
17. Fiore, A.; Jacob, D.J.; Liu, H.; Yantosca, R.; Fairlie, T.D.; Li, Q. Variability in surface ozone background over the United States: Implications for air quality policy. J. Geophys. Res. Space Phys. 2003, 108, 478. [CrossRef]

18. Fiore, A.; Oberman, J.; Lin, M.; Zhang, L.; Clifton, O.; Jacob, D.; Naik, V.; Horowitz, L.; Pinto, J.; Milly, G. Estimating North American background ozone in U.S. surface air with two independent global models: Variability, uncertainties, and recommendations. Atmos. Environ. 2014, 96, 284-300. [CrossRef]

19. Lefohn, A.S.; Cooper, O.R. Introduction to the special issue on observations and source attribution of ozone in rural regions of the western United States. Atmos. Environ. 2015, 109, 279-281. [CrossRef]

20. Lefohn, A.S.; Emery, C.; Shadwick, D.; Wernli, H.; Jung, J.; Oltmans, S.J. Estimates of background surface ozone concentrations in the United States based on model-derived source apportionment. Atmos. Environ. 2014, 84, 275-288. [CrossRef]

21. Zhang, L.; Jacob, D.J.; Downey, N.V.; Wood, D.A.; Blewitt, D.; Carouge, C.C.; van Donkelaar, A.; Jones, D.B.A.; Murray, L.T.; Wang, Y. Improved estimate of the policy-relevant background ozone in the United States using the GEOS-Chem global model with $1 / 2^{\circ} \times 2 / 3^{\circ}$ horizontal resolution over North America. Atmos. Environ. 2011, 45, 6769-6776. [CrossRef]

22. Anenberg, S.C.; West, J.J.; Fiore, A.M.; Jaffe, D.A.; Prather, M.J.; Bergmann, D.; Cuvelier, K.; Dentener, F.J.; Duncan, B.N.; Gauss, M.; et al. Intercontinental Impacts of Ozone Pollution on Human Mortality. Environ. Sci. Technol. 2009, 43, 6482-6487. [CrossRef]

23. West, J.J.; Fiore, A.M.; Horowitz, L.W.; Mauzerall, D.L. Global health benefits of mitigating ozone pollution with methane emission controls. Proc. Natl. Acad. Sci. USA 2006, 103, 3988-3993. [CrossRef]

24. Collins, W.J.; Derwent, R.G.; Garnier, B.; Johnson, C.E.; Sanderson, M.G.; Stevenson, D.S. Effect of stratosphere-troposphere exchange on the future tropospheric ozone trend. J. Geophys. Res. 2003, 108, D8528. [CrossRef]

25. Johnson, C.E.; Collins, W.J.; Stevenson, D.S.; Derwent, R.G. Relative roles of climate and emissions changes on future tropospheric oxidant concentrations. J. Geophys. Res. Space Phys. 1999, 104, 18631-18645. [CrossRef]

26. Lamarque, J.-F.; Hess, P.; Emmons, L.; Buja, L.; Washington, W.; Granier, C. Tropospheric ozone evolution between 1890 and 1990. J. Geophys. Res. Space Phys. 2005, 110, 08304. [CrossRef]

27. Stevenson, D.; Doherty, R.; Sanderson, M.; Johnson, C.; Collins, B.; Derwent, D.; Collins, W. Impacts of climate change and variability on tropospheric ozone and its precursors. Faraday Discuss. 2005, 130, 41. [CrossRef] [PubMed]

28. Stevenson, D.S.; Young, P.J.; Naik, V.; Lamarque, J.-F.; Shindell, D.T.; Voulgarakis, A.; Skeie, R.B.; Dalsoren, S.B.; Myhre, G.; Berntsen, T.K.; et al. Tropospheric ozone changes, radiative forcing and attribution to emissions in the Atmospheric Chemistry and Climate Model Intercomparison Project (ACCMIP). Atmos. Chem. Phys. Discuss. 2013, 13, 3063-3085. [CrossRef]

29. Young, P.J.; Archibald, A.T.; Bowman, K.W.; Lamarque, J.-F.; Naik, V.; Stevenson, D.S.; Tilmes, S.; Voulgarakis, A.; Wild, O.; Bergmann, D.; et al. Pre-industrial to end 21st century projections of tropospheric ozone from the Atmospheric Chemistry and Climate Model Intercomparison Project (ACCMIP). Atmos. Chem. Phys. Discuss. 2013, 13, 2063-2090. [CrossRef]

30. Derwent, R.G.; Witham, C.S.; Utembe, S.R.; Jenkin, M.E.; Passant, N.R. Ozone in Central England: The impact of 20 years of precursor emission controls in Europe. Environ. Sci. Policy 2010, 13, 195-204. [CrossRef]

31. Gery, M.W.; Whitten, G.Z.; Killus, J.P.; Dodge, M.C. A photochemical kinetics mechanism for urban and regional scale computer modeling. J. Geophys. Res. Space Phys. 1989, 94, 12925. [CrossRef]

32. ENVIRON. CAMx User's Guide Version 6.2; Environ International Corporation: Novato, CA, USA, 2015.

33. Jenkin, M.; Watson, L.; Utembe, S.; Shallcross, D. A Common Representative Intermediates (CRI) mechanism for VOC degradation. Part 1: Gas phase mechanism development. Atmos. Environ. 2008, 42, 7185-7195. [CrossRef]

34. Andersson-Skold, Y.; Simpson, D. Comparison of the Chemical Schemes of the EMEP MSC-W and IVL Photochemical Trajectory Models; EMEP/MSC-W Note 1/97; Norwegian Meteorological Institute: Oslo, Norway, 1997.

35. Emmerson, K.M.; Evans, M.J. Comparison of tropospheric gas-phase chemistry schemes for use within global models. Atmos. Chem. Phys. Discuss. 2009, 9, 1831-1845. [CrossRef]

36. Jenkin, M.E.; Young, J.C.; Rickard, A.R. The MCM v3.3.1 degradation scheme for isoprene. Atmos. Chem. Phys. Discuss. 2015, 15, 11433-11459. [CrossRef] 
37. Menut, L.; Bessagnet, B.; Khvorostyanov, D.; Beekmann, M.; Blond, N.; Colette, A.; Coll, I.; Curci, G.; Forêt, G.; Hodzic, A.; et al. CHIMERE 2013: A model for regional atmospheric composition modelling. Geosci. Model Dev. 2013, 6, 981-1028. [CrossRef]

38. Emmons, L.K.; Walters, S.; Hess, P.G.; Lamarque, J.-F.; Pfister, G.G.; Fillmore, D.; Granier, C.; Guenther, A.; Kinnison, D.; Laepple, T.; et al. Description and evaluation of the Model for Ozone and Related chemical Tracers, version 4 (MOZART-4). Geosci. Model Dev. 2010, 3, 43-67. [CrossRef]

39. Stockwell, W.R. A homogeneous gas phase mechanism for use in a regional acid deposition model. Atmos. Environ. 1986, 20, 1615-1632. [CrossRef]

40. Goliff, W.S.; Stockwell, W.R.; Lawson, C.V. The regional atmospheric chemistry mechanism, version 2. Atmos. Environ. 2013, 68, 174-185. [CrossRef]

41. Carter, W.P.L. Development of a condensed SAPRC-07 chemical mechanism. Atmos. Environ. 2010, 44, 5336-5345. [CrossRef]

42. Ammann, M.; Cox, R.A.; Crowley, J.N.; Jenkin, M.E.; Mellouki, A.; Rossi, M.J.; Troe, J.; Wallington, T.J. Evaluated kinetic and photochemical data for atmospheric chemistry: Volume VI-heterogeneous reactions with liquid substrates. Atmos. Chem. Phys. Discuss. 2013, 13, 8045-8228. [CrossRef]

43. Derwent, R.G.; Utembe, S.R.; Jenkin, M.E.; Shallcross, D.E. Tropospheric ozone production regions and the intercontinental origins of surface ozone over Europe. Atmos. Environ. 2015, 112, 216-224. [CrossRef]

44. Curtis, A.R.; Sweetenham, W.P. FACSIMILE Release H User's Manual; AERE Report R11771; H.M. Stationery Office: London, UK, 1987.

45. Bloss, C.; Wagner, V.; Jenkin, M.E.; Volkamer, R.; Bloss, W.J.; Lee, J.D.; Heard, D.E.; Wirtz, K.; Martín-Reviejo, M.; Rea, G.; et al. Development of a detailed chemical mechanism (MCMv3.1) for the atmospheric oxidation of aromatic hydrocarbons. Atmos. Chem. Phys. Discuss. 2005, 5, 641-664. [CrossRef]

(C) 2020 by the author. Licensee MDPI, Basel, Switzerland. This article is an open access article distributed under the terms and conditions of the Creative Commons Attribution (CC BY) license (http://creativecommons.org/licenses/by/4.0/). 